Original Research Article

\title{
A prospective cross-sectional study on prescribing pattern of antibiotics on patients suffering from ENT infections in tertiary care hospital, Pokhara, Nepal
}

\author{
Surendra P. Gupta ${ }^{1 *}$, Salikram Poudel ${ }^{1}$, Anil P. Gupta ${ }^{1}$, Basanta Bashyal ${ }^{1}$, Bishal Baskota ${ }^{1}$, \\ Anil K. Sah ${ }^{2}$, Subash Pandaya ${ }^{3}$, Dhiraj Shrestha ${ }^{4}$
}

\begin{abstract}
${ }^{1}$ Department of Pharmacy, Crimson College of Technology, Butwal, Rupandehi, Nepal ${ }^{2}$ Department of Pharmaceutical Care, Kathmandu University, Dhulikhel, Kathmandu, Nepal ${ }^{3}$ Department of Pharmaceutical Sciences, North South University, Dhaka, Bangladesh ${ }^{4}$ Department of Pharmaceutics, N.E.T. Pharmacy College, Raichur, Karnataka, India
\end{abstract}

Received: 19 July 2017

Revised: 01 August 2017

Accepted: 22 August 2017

*Correspondence to: Surendra P. Gupta, Email: surendrag150@ gmail.com

Copyright: (C) the author(s), publisher and licensee Medip Academy. This is an openaccess article distributed under the terms of the Creative Commons Attribution NonCommercial License, which permits unrestricted noncommercial use, distribution, and reproduction in any medium, provided the original work is properly cited.

\begin{abstract}
Background: This survey was designed to assess and evaluate the prescribing pattern of antibiotics used in patients suffering from ENT (Eye, Nose, and Throat) infections in ENT outpatient departments (OPD) at Manipal Teaching Hospital (MTH), Phulbari, Pokhara, Nepal.

Methods: A prospective cross-sectional study was conducted in out-patients of ENT department at MTH for 6 month in which a total of 216 prescriptions were observed randomly and data filled patient profile forms were collected and analyzed.
\end{abstract}

Results: Out of 216 patients, 126(58.33\%) were male and $90(41.67 \%)$ were female. Patients of age group 21-30 were maximum $(29.16 \%)$ followed by age group of 11-20 (22.22\%). Only $6.7 \%$ of drugs were prescribed from their generic names. Data analysis revealed that about $72.24 \%, 24.53 \%$ and $3.23 \%$ of prescription contained one, two and three antibiotic drugs respectively. All together 970 drugs were prescribed in 216 prescriptions out of which 251 $(25.87 \%)$ were antibiotics drugs. This suggested that the average no. of antibiotics per prescription was 1.16. Among prescribed antibiotics, Amoxicillin (7.56\%) of penicillin group, Azithromycin (8.36\%) of macrolides, Cefuroxime $(9.56 \%)$ of $2^{\text {nd }}$ generation cephalosporin followed by Cefpodoxime $(32.27 \%)$ of $3 \mathrm{rd}$ generation cephalosporin and Ofloxacin $(6.37 \%)$ of quinolones group were frequently prescribed. From analysis, we found that other concomitant medications were also prescribed such analgesics, antihistamines, PPI (Proton Pump Inhibitors) and vitamins, minerals and dietary enzymes. The prescribed antibiotics accounted for large percentage of oral dosage forms $(89.90 \%)$ followed parental injection dosage forms $5.05 \%$.

Conclusions: Prescribing more than one antibiotics was commonly encountered indicating the occurrence of polypharmacy which were based on empirical therapy without any culture and sensitivity test report. Therefore, local hospital culture sensitivity database for ENT infections has to be developed and prescribing with generic name from existing essential drug list or formulary should be encouraged for rational drug therapy.

Keywords: Antibiotics, ENT infections, Empirical therapy, Generic names, MTH, Prescribing pattern, Polypharmacy

\section{INTRODUCTION}

ENT department in tertiary care hospital is a separate department concerning with management, control, prevention of infection related to ear, nose and throat such as otitis media, upper and lower respiratory tract infection, bronchitis, tonsillitis, pharyngitis, laryngitis, sinusitis etc. ${ }^{1}$ Diseases of the ear, nose and throat affect the functioning of adults as well as children, often with significant impairment of the daily life of affected patients. ${ }^{2}$ The prescribing pattern deals with monitoring, evaluating and suggesting modifications in the prescribing pattern, so as 
to make patient care safe, effective and cost effective. ${ }^{3}$ Irrational prescribing pattern has been widely reported from both developed as well as developing countries. ${ }^{4}$ Inappropriate use of antibiotics is a great public health concern because of its increased chances of development of antibiotic resistance in a community. ${ }^{5}$ According to the world health report of 2010, it has been estimated that respiratory infections were the fourth major cause of mortality which is responsible for global number of deaths and on other hand it also generated that 94.6 disability adjusted life years lost worldwide. ${ }^{6}$

An upper respiratory infection (URI) is a viral or bacterial infection that affects the nose, throat (pharynx), sinuses, and voice box (larynx). The most familiar upper respiratory infections include the common cold (Rhino pharyngitis), infection of the throat (Pharyngitis), tonsils (tonsillitis), the maxillary sinuses behind the nose (sinusitis), and the larynx (laryngitis). Ear infections (acute otitis media) are another manifestation of URI. ${ }^{7,8}$ According to a recent study, acute respiratory infections are the most frequent reason for seeking medical attention and are the reason for $75 \%$ of the antibiotic prescriptions each year. ${ }^{9}$ As these ENT infections are generally caused by micro-organisms such as bacteria, fungi and viruses, the ultimate aim of the drug therapy of ENT infections is to eradicate infections and minimize the morbidity and the complications associated with them by using appropriate antimicrobials. ${ }^{10,11}$

Drug utilization studies are important to facilitate rational use of drugs in population. The drug utilization studies also relate to the beneficial or adverse effects of drug use in health care system. ${ }^{12}$ Concept of rational drug prescribing is new in developing countries like Nepal, though several steps have been taken in the recent past towards ensuring rational drug use. ${ }^{13}$ According to figure gathered by survey (from 1992 to 1996) presented to the World Health Organization (WHO), about $13 \%$ of cases of URTI are prescribed with antibiotics wrongly and irrationally after long term study of use of antibiotic in 13 low-middle and high income countries. ${ }^{14}$

Drug utilization usually varies among different countries and even among health institutions within a country. ${ }^{15}$ Antibiotic is a highly misused medicine in present scenario. ${ }^{16}$ Over use of antibiotics is a problem that continues to gain attention from national organizations as a significant threat to public health. ${ }^{17}$ In Afghanistan, Over-consumption of antibiotics is a realistic threat in aidsupported settings and may be linked to the observed high prevalence of antibiotic resistance there. ${ }^{18,19}$ In a publication from Thailand, more than $80 \%$ of the prescriptions for upper respiratory tract infections contained antimicrobials. ${ }^{20}$ In practice, one of the most common irrational uses of medicines is excessive prescription of antimicrobials. ${ }^{21}$ According to a recent report by the $\mathrm{WHO}$ on antimicrobial resistance, death from an infectious illness is twice as likely to occur when a resistant bacteria is the causative pathogen. ${ }^{22}$
As irrational use of antibiotics increases the chances of development of antibiotic resistance in a community, so it needs of studying the antibiotic prescribing pattern of the physicians, so as to ensure judicious use of antimicrobial agents. ${ }^{23}$ Assessment of drug use patterns is becoming increasingly necessary to promote rational drug use and before activities are started to promote rational drug use, an effort should be made to describe and quantify the already existing situation. ${ }^{24,25}$ Therefore, it is important to evaluate and monitor the prescription patterns from time to time to increase the therapeutic benefit and decrease the adverse effects to optimize the medical services for the patients. ${ }^{26}$ In 2015, Chowdhury et al, conducted a survey in Bangladesh and their findings involved significant percentage of patients receiving antibiotics in Bangladesh. ${ }^{27}$ Such finding was relevant to the reports on antibiotic usages in other parts of Asia, Europe or America. $^{28}$ It is a concerning matter that almost $27 \%$ patients are unconscious about the completion of antibiotic course. This unconsciousness leads to antibiotic resistance which might be a vulnerable threat of public health condition in future. ${ }^{29,30}$

The objective of the present study was to evaluate the patterns of drug prescribing practices in ENT OPD and generate up to date information on drug use in the ENT outpatient service and indications for use. Nowadays, large no. of people suffering from diseases of ear, nose and throat and very few studies has been conducted in this area so as to help clinician to select most suitable drug, this study has been designed which would also encourage good evidence based practice and facilitate appropriateness of drugs and was carried out in ENT outpatient department at MTH, Phulbari, Pokhara, Nepal.

\section{METHODS}

A prospective cross-sectional hospital based study was conducted in order to evaluate prescription pattern of antibiotic drugs in patients with various ENT infections. On the basis of inclusion and exclusion criteria, prescriptions were collected from all patients of either sexes attended to ENT outpatient department at MTH in which a total of 216 prescriptions were observed randomly from the ENT ward and data filled patient profile form with various details (like name, age, sex, weight, reason for admission, past medical history) were collected and analyzed. The methodology for the current survey was adapted in a way where statistical procedures were solely used. For better understanding, the methodology has been designed to follow a number of steps including selection site, duration of survey, sampling, data collection, data processing and graphical representation and specification.

\section{Study site}

The study was conducted at MTH (A 849-bedded tertiary care teaching hospital), Phulbari, Pokhara, Kaski, Nepal to ENT outpatient department. 


\section{Duration of survey}

The present survey was held for six months, from $1^{\text {st }}$ June to $1^{\text {st }}$ December 2015 . This period of time partly covered most important seasons including rainy and winter season of Pokhara valley. As a result, this time span covered general and seasonal diseases like cold, flu, hay fever etc. of our country. Nevertheless, most seasonal diseases are associated with ENT infections.

\section{Study design and data collection}

Designing the pattern of sampling is a definite plan for obtaining a sample from a given area. The information that was collected from the survey areas was related to the prescribing and marketing pattern of antibiotics and other drugs of Pokhara. A number of criteria were considered for analyzing the prescriptions that include; presence of antibiotics, number of prescriptions containing multiple antibiotics, class of antibiotic, dosage forms and combination of other drugs.

\section{Inclusion and exclusion criteria}

The patients taken in to consideration for the present survey included male and female out-patient of all ages. The population of patients also covered pregnant or lactating woman of both of urban or rural communities. Taking consideration of exclusion criteria, some group of patients were also excluded from study such as patients with mental retardation, drug addiction, tuberculosis and other chronic infections.

The method for entire study for data collection was carried out in three phases as discussed below;

\section{Phase I}

\section{Pilot study and literature review}

A pilot study was carried out for a period of three weeks to find the feasibility and scope of the project followed by designing the study proposal and its necessity was explained to the department of pharmacy using final protocol.

\section{Procuring the consent from hospital authority}

The study proposal was submitted to the medical superintendent of the hospital and obtained permission to utilize the hospital facilities through a letter.

\section{Literature survey}

An exhaustive literature survey was carried out regarding our study title for collecting required information from various sources including journals and so on.

\section{Phase II}

The study was planned to investigate 300 patient's records to increase the precision of the parameter from the outpatient's ward of the ENT department of the hospital but due to short span of time and low patient visits, a total of 216 prescriptions written by qualified medical doctors were collected randomly from the ENT ward.

\section{Assessing the prescriptions}

Prospective data from 216 prescriptions were obtained with regard to age, past medical history, present diagnosis and prescribed drugs. Latest edition of CIMS drugs manual was used to decode brand name of drugs to generic names for the purpose of analysis.

\section{Phase III}

\section{Data entry}

The prescriptions of the selected patients were collected from the outpatient ENT department of MTH and records of such patients were maintained with due attention to inclusion and exclusion criteria using a patient profile form (Table 1) with following variables:

- $\quad$ Patient's details: Name, age, sex and residency

- Date of admission

- Hospital no.

- Diagnosis

- Department

- Dosage form

- Prescription character

- $\quad$ Strength and dose

- Dispensed quantity

Table 1: A sample of patient profile form.

\begin{tabular}{l}
\begin{tabular}{|l|} 
Patient profile form \\
Department of pharmacy, Crimson College of \\
Technology, Butwal-13, Rupandehi, Nepal
\end{tabular} \\
$\begin{array}{l}\text { Patient name: Age: Mex: Hospital Date: } \quad \text { Mo.: } \\
\text { Races: Brahman/ Chhetri/ Newar/ Mongolian (Grg, } \\
\text { Magar, Tamang, Sherpa) Other }\end{array}$ \\
\hline Weight \\
\hline Address Department \\
\hline Provisional diagnosis: \\
\hline Final diagnosis: \\
\hline Past history: \\
\hline Present history: \\
\hline Past medication \\
\hline No. Drug name, Strength and Dose \\
\hline Prescribed medication \\
\hline No. \\
\hline
\end{tabular}




\section{Data specification}

After collecting the patient's records in patient profile form, we analyzed each record thoroughly and the following parameters were taken into account while sorting the data based on the manual of WHO drug indicators.

- Average number of drugs per encounter.

- Percentage of drugs prescribed by generic names.

- Percentage of encounters with one or more antibiotic prescribed.

- Percentage of both oral and parenteral form of antibiotics prescribed to ENT outpatients.
- Percentage of drugs prescribed from essential drug lists of Nepal.

\section{Data evaluation}

The data collected from all the prescriptions were evaluated by Microsoft Excel Software. All the information regarding the prescribing pattern of antibiotics in a prescription including the study of the demographic characteristics and diagnosis of the patient with antibiotics, distribution of antibiotics in the different age groups and gender, and essential drugs included per prescription were summarized.

Table 2: Tabular representation of demographic data of patients.

\begin{tabular}{|llllllllll|l|}
\hline Gender & $\mathbf{0 - 1 0}$ & $\mathbf{1 1 - 2 0}$ & $\mathbf{2 1 - 3 0}$ & $\mathbf{3 1 - 4 0}$ & $\mathbf{4 1 - 5 0}$ & $\mathbf{5 1 - 6 0}$ & Above 60 & $\begin{array}{l}\text { No. of } \\
\text { patients }\end{array}$ & \% \\
\hline Male & 13 & 26 & 35 & 18 & 14 & 10 & 10 & 126 & 58.33 \\
\hline Female & 11 & 22 & 28 & 11 & 10 & 5 & 3 & 90 & 41.67 \\
\hline Total & 24 & 48 & 63 & 29 & 24 & 15 & 13 & 216 & 100 \\
\hline$\%$ & 11.11 & 22.22 & 29.16 & 13.42 & 11.11 & 6.90 & 6.08 & 100 & \\
\hline
\end{tabular}

Table 3: Distribution of drugs/antibiotics per prescription among ENT infected patients.

\begin{tabular}{|lll|llll|}
\hline Department & $\begin{array}{l}\text { Total no. } \\
\text { of drugs }\end{array}$ & $\begin{array}{l}\text { \% of } \\
\text { drugs }\end{array}$ & $\begin{array}{l}\text { Average no. of } \\
\text { drugs per } \\
\text { prescription }\end{array}$ & $\begin{array}{l}\text { No. of } \\
\text { prescribed } \\
\text { antibiotics }\end{array}$ & $\begin{array}{l}\text { \% of } \\
\text { antibiotics } \\
\text { drugs }\end{array}$ & $\begin{array}{l}\text { Average no. of } \\
\text { antibiotics per } \\
\text { prescription }\end{array}$ \\
\hline ENT & 970 & 100 & 4.5 & 251 & 25.87 & 1.16 \\
\hline
\end{tabular}

\section{RESULTS}

This survey was mainly designed to see the prescription pattern of antibiotic drugs which are prescribed to the patients of ENT outpatients department at MTH where a total of 216 prescription records were collected, scrutinized and analyzed over a period of 6 months. Out of 216 patients, $126(58.33 \%)$ were male and $90(41.67 \%)$ were female (including children, adults, geriatric patients) as shown in (Table 2).

Mostly patients of age group 21-30 (29.16\%) and 11-20 $(22.22 \%)$ were encountered (Table 2$)$. In our study, we found that most of patients were encountered from urban areas $(52 \%)$ and then followed by rural areas (48\%) (Figure 1).

In the patient's information section, almost all the patients were suffering from ear, nose and throat infections. It was observed that the medication for all these common ENT infections involved antibiotic drugs along with other drugs. Altogether 970 drugs were prescribed in 216 prescriptions out of which 251 (25.87\%) were antibiotics drugs. This suggested that the average no. of drugs per prescription was 4.5 and the average no. of antibiotics per prescription was 1.16 (Table 3).

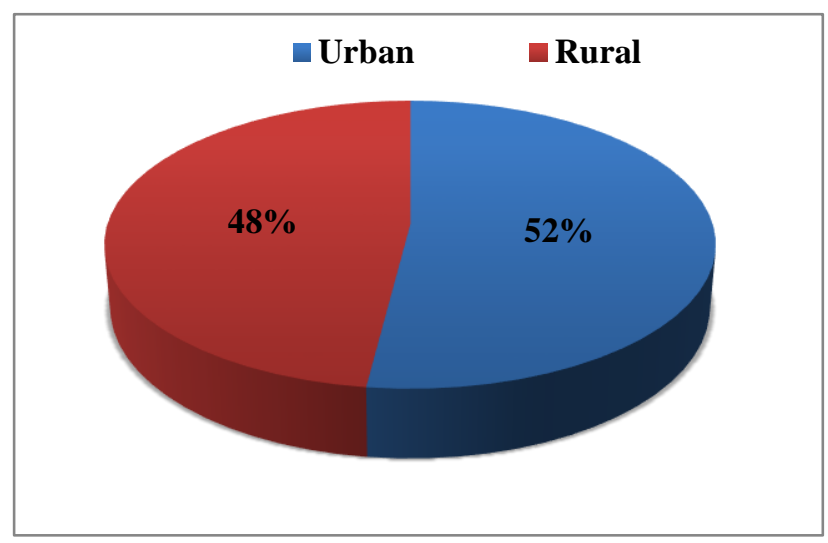

Figure 1: Habitat wise distribution of patients.

In our prospective study, altogether 527 out of 970 drugs were included from Essential Drug List of Nepal (Fourth Revision, 2011) and the average no. of essential medicines per prescription was 2.44 (Table 4). On analyzing the prescriptions, we found the prescriptions containing single and multiple antibiotic drugs as well as prescriptions 
containing some other cateogry of drugs like analgesics and anti-inflammatory, drugs acting on respiratory system, antihistamines predominantly along with the antibiotics. From this analysis, we found that $72.24 \%$ prescription contained single antibiotic drug, $24.53 \%$ contained two antibiotic drugs and $3.23 \%$ contained three antibiotic drugs as shown in (Figure 2). Apart from antibiotics, other concomitant medications were prescribed that covered large part of prescriptions. From analysis we found that $85.64 \%$ of prescriptions contained drugs acting on ANS (Autonomic Nervous System) like ephedrine, oxymetazoline etc, $83.33 \%$ contained analgesics, $74.07 \%$ contained antihistamines, $64.81 \%$ contained PPI (Proton Pump Inhibitors) and $46.30 \%$ contained vitamins, minerals and dietary enzymes as shown in (Figure 3).

Table 4: Distribution of prescribed drug according to essential medicine list of Nepal.

\begin{tabular}{|llll|}
\hline $\begin{array}{l}\text { Types of } \\
\text { Prescribed } \\
\text { drugs }\end{array}$ & $\begin{array}{l}\text { Number } \\
\text { of drugs }\end{array}$ & $\begin{array}{l}\text { Drugs } \\
\text { per } \\
\text { prescription }\end{array}$ & $\begin{array}{l}\text { \% of } \\
\text { prescribed } \\
\text { drugs }\end{array}$ \\
\hline $\begin{array}{l}\text { Essential } \\
\text { medicine }\end{array}$ & 527 & 2.44 & 54.33 \\
\hline $\begin{array}{l}\text { Non- } \\
\text { Essential } \\
\text { medicine }\end{array}$ & 443 & 2.06 & 45.67 \\
\hline Total & 970 & 4.5 & 100 \\
\hline
\end{tabular}

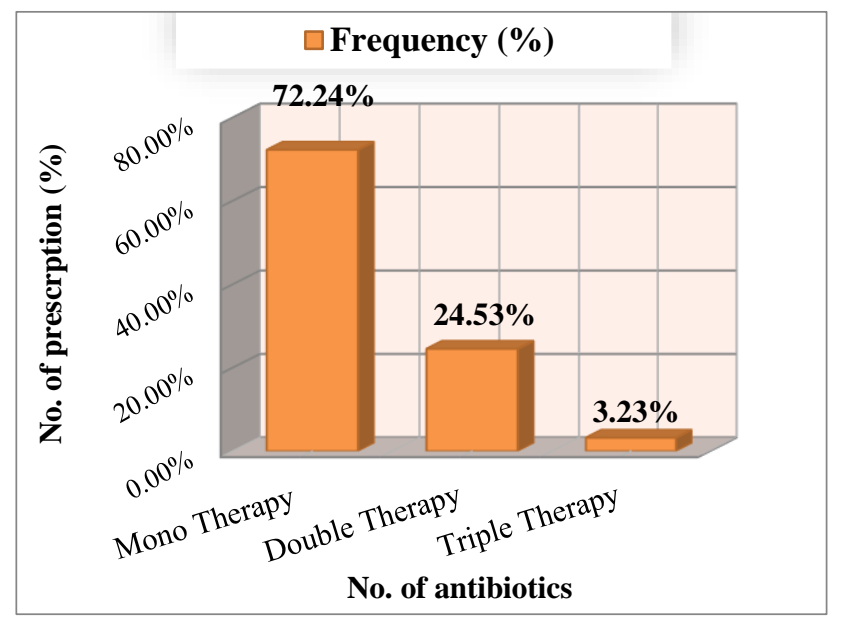

Figure 2: Polypharmacy with antibiotics.

\section{Classification of prescribed antibiotics}

Among the 216 collected prescriptions, all prescriptions were found containing one or more antibiotic drugs. A total number of 251 antibiotic drugs were present which belonged to different classes. Some important classes of antibiotic drugs and their respective frequencies of usage are shown in (Figure 4). Among prescribed antibiotics, Amoxicillin $(7.56 \%)$ of penicillin group, Azithromycin $(8.36 \%)$ of macrolides, Cefuroxime $(9.56 \%)$ of $2^{\text {nd }}$ generation cephalosporin followed by Cefpodoxime $(32.27 \%)$, Ceftriaxone $(18.33 \%)$ of $3^{\text {rd }}$ generation cephalosporin and Ofloxacin $(6.37 \%)$ of quinolones group were frequently prescribed. The antibiotics prescribed were available in different dosage forms with their respective frequencies as shown in (Figure 5).

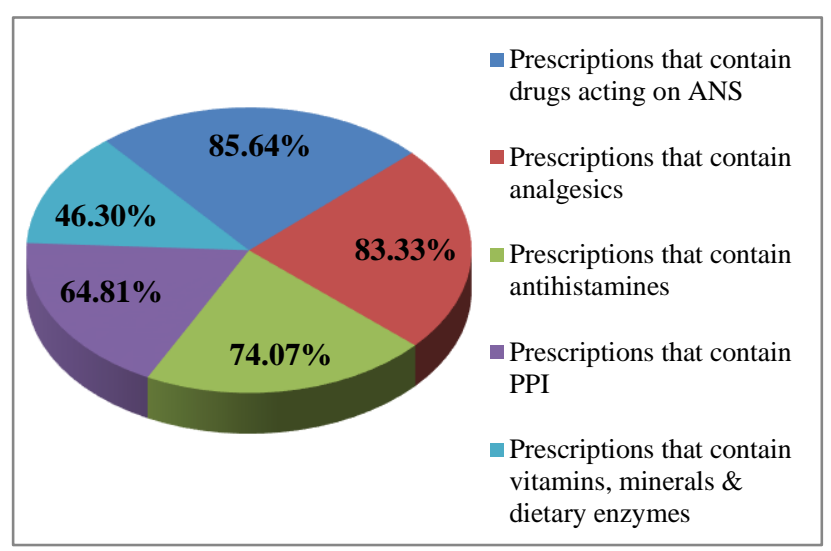

Figure 3: Percentage of other concomitant medications prescribed with antibiotics.

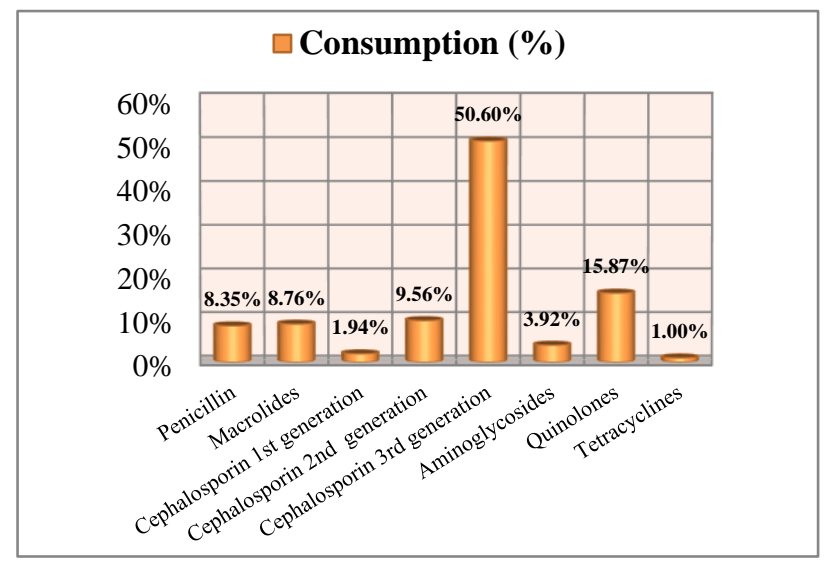

Figure 4: Important classes of antibiotic drugs that were commonly prescribed for the treatment against infectious diseases associated with ENT.

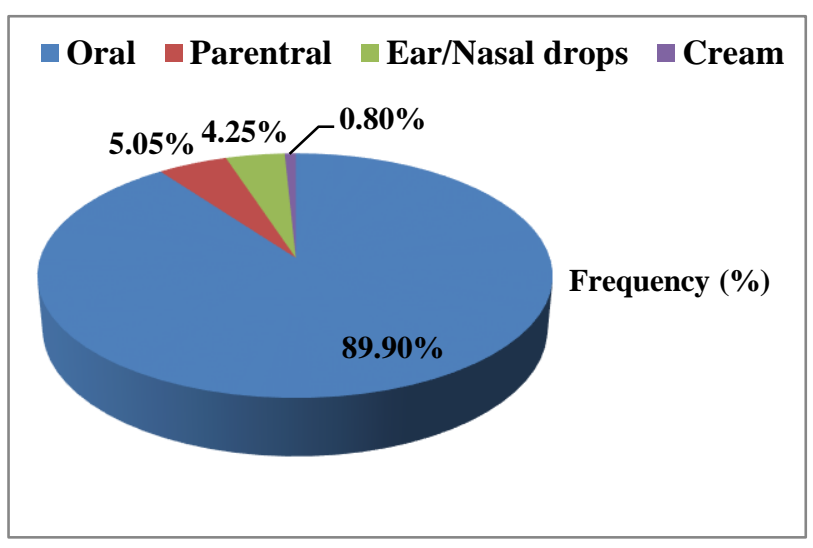

Figure 5: Prescribed antibiotics in different dosage forms.

From Figure 6, it was found that drugs were mainly introduced by their brand names as most of our physicians 
mentioned the brand name $(93.3 \%)$ of the medicine instead of the generic name $(6.7 \%)$ while prescribing antibiotics or any other drugs.

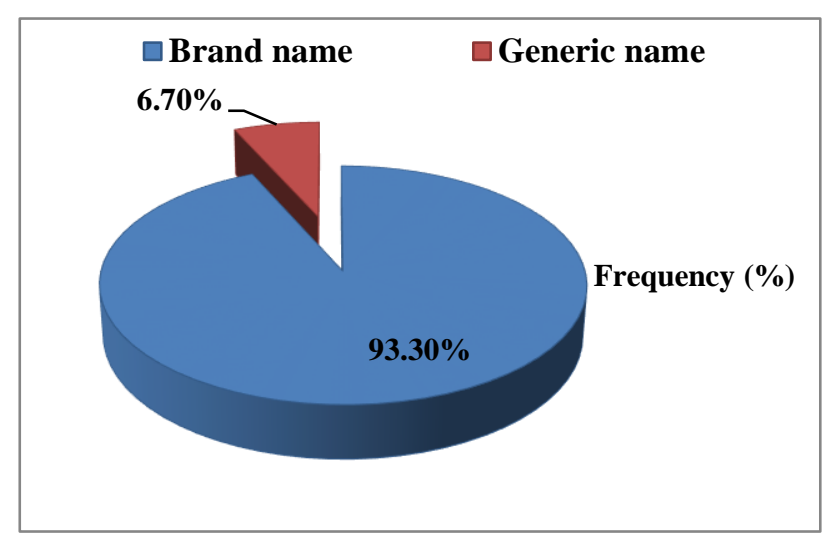

Figure 6: Percentage of prescription declaring brand name or the generic name of drugs.

\section{WHO prescribing indicators}

- $\quad$ Average number of drugs per encounter $=4.5$.

- Percentage of drugs prescribed by generic names $=$ $6.7 \%$.

- $\quad$ Percentage of encounters with one or more antibiotic prescribed $=100 \%$.

- Percentage of both oral and parenteral form of antibiotics prescribed to ENT outpatients $=89.90 \%$ and $5.05 \%$ respectively.

- $\quad$ Percentage of drugs prescribed from essential drug lists of Nepal $=54.33 \%$.

\section{DISCUSSION}

A prescription which is given by a doctor or physician is taken as an indication of the doctor's or physician's attitude towards the disease and the role of drugs in its treatment. ${ }^{31}$ The central priority of health care system is providing the right medicine to the right people at the right time. $^{32}$

The source of data for the current survey involved prescriptions of patients suffering from infectious diseases associated with ENT that were collected from ENT department of MTH in Pokhara valley. In our study, total 216 medication orders were analyzed. Demographic characteristics showed that male $(58.33 \%)$ was found to be the predominant sufferers from ENT infections than female $(41.67 \%)$. Similar findings (male- $73.33 \%$ and female-26.67\%) were also reported in current study conducted at government and private hospitals of Dhaka city by Begum MM et al. 2017. ${ }^{33}$ We included the ENT patients of all ages in our study, in which the maximum number of patient observed were from age group of 21-30 years $(29.16 \%)$ followed by age group 11-20 years $(22.22 \%)$. In other similar study of Maharashtra (India), the antibiotics exposure pattern among different age groups showed that people of age group 21-40 years were prominent in attending OPD of ENT. ${ }^{34} \mathrm{We}$ found that most of ENT patients $(52.0 \%)$ were encountered from urban areas followed by $48.0 \%$ from rural areas that may be due to easy access to hospital by patients of urban areas.

During the course of study, we observed that the most common antibiotic class frequently prescribed were $\beta$ lactams (Cephalosporin of $2^{\text {nd }}$ and $3^{\text {rd }}$ generation, Penicillin) followed by quinolones, macrolides groups. In a similar study conducted by Ain et al. and Khan et al. it was observed that $\beta$-lactams were the most commonly prescribed antibiotics. ${ }^{35,36}$

On the basis of the results of prescription analysis, we found that all prescriptions contained at least one antibiotic. About $72.2 \%$ prescriptions showed monotherapy of antibiotic, $24.53 \%$ prescriptions showed double therapy of antibiotics and $3.23 \%$ prescriptions showed triple therapy of antibiotics. This showed a great prevalence of polypharmacy practice which coincides with the studies conducted by Ain et al, and Yadav et al. ${ }^{35,37}$ The average number of antibiotic prescribed per prescription was found to be 1.16 in our study which resembled with the result of study conducted by pal et al. ${ }^{38}$ The mean number of drugs per prescription was 4.5 indicating empirical nature of therapy. In similar studies conducted by Deshmukh et al. and Ansari et al, it was found that the average number of drugs per prescription was 3.57 and 5.05respectively. ${ }^{39,40}$

In our study, it was found that most of medications were prescribed in brand names $(93.30 \%)$ and least in generic names $(6.70 \%)$ which coincides with the report from the survey conducted by Padwal SL et al. and Raza UA et al. ${ }^{41,42} \mathrm{We}$ found that about $54.33 \%$ of medications were prescribed from essential drug list of Nepal in ENT department and about 2.44 essential medicines were prescribed per prescription. In similar type of study conducted by Pal et al., about $72.46 \%$ of medications were prescribed from essential drug list. ${ }^{38}$ In our study, most of the antibiotics were prescribed in oral dosage forms $(89.90 \%)$ followed by injection form $(5.05 \%)$. Similar type of results was found in a study conducted by Abubakar et al., in which $78.40 \%$ of prescribed drugs were in oral form followed by $14.0 \%$ in eardrops form and $7.6 \%$ in intravenous injection form. ${ }^{43}$

From analysis we found that apart from antibiotics, other concomitant medications were also prescribed. About $85.64 \%$ of prescriptions contained drugs acting on ANS, $83.33 \%$ contained analgesics, $74.07 \%$ contained antihistamines, $64.81 \%$ contained PPI and $46.30 \%$ contained vitamins, minerals and dietary enzymes. This is in concordance with the study conducted by Lisha JJ et al, who have reported that about $78.50 \%$ of prescriptions contained Analgesics, 57.90\% contained antipyretics, $37.30 \%$ contained cough suppressants, $18.90 \%$ contained antihistamines and $18.90 \%$ contained acid suppressants. ${ }^{44}$ 


\section{CONCLUSION}

The aim of the study was to carry out analysis and evaluation of drug prescribing pattern in ENT outpatients. The study concluded that antibiotics were the most prescribed drugs for ENT patients. The present observation indicated that majority of patients were not using the regimen in accordance with the current guidelines. Prescribing multiple antibiotics without any culture and sensitivity report was commonly encountered in this study indicating the practice of polypharmacy. Therefore, local hospital culture sensitivity database for ENT infections has to be developed to help selection of empirical antimicrobials and their rational use. As antibiotic resistance has become a big health issue in Nepal, dedicated training hours on prescribing pattern of antimicrobials in ENT infections for doctors along with regular prescription audit and review by pharmacist will help to promote judicial and rationale use of antimicrobials in the long run. Antimicrobial drugs prescribing by generic name usually from existing essential drug list or formulary should be encouraged for rational drug therapy.

\section{ACKNOWLEDGEMENTS}

Authors would like to acknowledge to the supervisor Anil Kumar Sah, Department of Pharmaceutical Care, Kathmandu University, Dhulikhel, Kathmandu, Nepal, Director Dr. P.K Chakraborty, Chief of Pharmaceutical Care Service Dr. Kadir Alam, ENT Outpatient Department in charge Satya Piya Udal, and staffs of MTH, Pokhara, Kaski, providing an opportunity to carry out project work in the Hospital. Also, thankful to Principal Mr. Devi Bhandari, Coordinator of Pharmacy Department Mr. Mukesh Chaudhary, Lecturer Mr. Mohammad Mustafa, Mr. Pramod Aryal of Crimson College of Technology for their kind help.

Funding: No funding sources Conflict of interest: None declared

Ethical approval: The study was approved by the Institutional Ethics Committee of the Department of Pharmacy via a permission letter provided by medical superintendent of the Manipal Teaching Hospital, Pokhara, Nepal

\section{REFERENCES}

1. Grace NN, Bussmann RW. Traditional management of ear, nose and throat (ENT) diseases in Central Kenya. J. Ethnomed. 2006;2:54.

2. Sivakumar P, Razak TA, Perumal P. Drug utilization of antimicrobials in ENT patients. Asian Journal of Pharmaceutical and Clinical Research. 2011;4:123-25.

3. Remesh A, Salim S, Gayathri AM, Nair U, Retnavally KG. Antibiotics prescribing pattern in the in-patient department of a tertiary care hospital. Arch Pharma Practice. 2013;4(2):71-6.

4. Kumar J, Shaik MM, Kathi MC, Deka A, Gambhir SS. Prescribing indicators and patterns of use of antibiotics among medical outpatients in a teaching hospital of central Nepal. J of Col of Med Sci. 2010;6(2):7-13.

5. Gjelstad S, Dalen I, Lindbaek M. General physician's antibiotic prescription patterns for respiratory tract infections-still room for improvement. Scandinavian Journal of Primary Health Care. 2009;27:208-15.

6. Murray CJ, Barber RM, Foreman KJ, Ozgoren AA, Abd-Allah F, Abera SF. Global, regional, and national disability-adjusted life years (DALYs) for 306 diseases and injuries and healthy life expectancy (HALE) for 188 countries, 1990-2013: quantifying the epidemiological transition. The Lancet. 2015;386:2145-91.

7. Mossad SB. Upper respiratory tract infections. Clevel and Clinic. Department of Infectious Disease; 2015.

8. Hueston WJ, Mainous AG, Ornstein S, Pan Q, Jenkins R. Antibiotics for upper respiratory tract infections: follow-up utilization and antibiotic use. Archives of family medicine; 1999;8:426.

9. Hirschmann JV. Antibiotics for common respiratory tract infections in adults. Archives of internal medicine. 2002;162:256-64.

10. World Health Organization. Cough and cold remedies for the treatment of acute respiratory infections in young children. 2001;01-32.

11. Saketkhoo K, Januszkiewicz A, Sackner MA. Effects of drinking hot water, cold water, and chicken soup on nasal mucus velocity and nasal airflow resistance. CHEST Journal. 1978;74:408-10.

12. Lunde PK, Baksaas I. Epidemiology of Drug Utilization-Basic Concepts and Methodology. Acta Med Scandinavica. 1987;222:7-11.

13. Alam K, Mishra P, Prabhu M, Shankar PR, Palaian S, Bhandari RB, et al. A study on rational drug prescribing and dispensing in outpatients in a tertiary care teaching hospital of Western Nepal. Kathmandu University Medical Journal. 2006;4(4):436-43.

14. Gaash B. Irrational Use of Antibiotics. Indian J. Practicing Doctor. 2008;5(1):55-9.

15. Bergman U, Christenson I, Jansson B, Wiholm BE. Auditing hospital drug utilisation by means of defined daily doses per bed-day a methodological study. European J of Cli Phar.1980;17:183-7.

16. Chaurasia RC. Medication errors in children. IAP Bulletin Academy Today. 2006;2:28-9.

17. Coco AS, Horst MA, Gambler AS. Trends in broadspectrum antibiotic prescribing for children with acute otitis media in the United States, 1998-2004. BMC pediatrics. 2009;9:1.

18. Tariq TM. Bacteriologic profile and antibiogram of blood culture isolates from a children's hospital in Kabul. J Coll Physicians Surg Pak. 2014;24:396-9.

19. Sutter DE, Bradshaw LU, Simkins LH, Summers AM, Atha M, Elwood RL, et al. High incidence of multidrug-resistant gram-negative bacteria recovered from Afghan patients at a deployed US military hospital. Infection control and hospital epidemiology. 2011;32:854-60.

20. Issarachaikul R, Suankratay C. Antibiotic prescription for adults with upper respiratory tract infection and 
acute bronchitis at King Chulalongkorn Memorial Hospital, Thailand. Asian Biomed. 2013;7:15-20.

21. Sivagnanam G, Mohanasundaram J, Thirumalaikolundusubramanian $\mathrm{P}$, Raaj AA, Namasivayam K, Rajaram S. A survey on current attitude of practicing physicians upon usage of antimicrobial agents in southern part of India. Medscape General Medicine. 2004;6:1.

22. World Health Organization. Antimicrobial resistance global report on surveillance: 2014.

23. Austin DJ, Kristinsson KG, Anderson, RM. The relationship between the volume of antimicrobial consumption in human communities and the frequency of resistance. Proceedings of the National Academy of Sciences. 1999;96:1152-6.

24. Potharaju HR, Kabra SG. Prescription audit of outpatient attendees of secondary level government hospitals in Maharashtra. Indian $\mathbf{J}$ of Pha. 2011;43:150.

25. Desalegn AA. Assessment of drug use pattern using WHO prescribing indicators at Hawassa University teaching and referral hospital, south Ethiopia: a crosssectional study. BMC health services research 2013;13:1.

26. Krishnaswamy K, Kumar BD, Radhaiah G. A drug delivery percept and practices. Eur J Clin- Pharmacol 1985;29:363-70.

27. Chowdhury MMH, Kubra K, Islam MT, Rahman MM, Mehedy ME. Indiscriminate Uses of Antibiotics as a Threat to Public Health Demand Implementation of Effective Drug Practices and Enhancement of Public Awareness in Bangladesh. European Journal of Scientific Research. 2015;133:187-95.

28. Chang SC, Chang HJ, Lai MS. Antibiotic usage in primary care units in Taiwan. International Journal of Antimicrobial Agents. 1999;11:23-30.

29. Wise R, Hart T, Cars O, Streulens M, Helmuth R, Huovinen P, et al. Antimicrobial resistance is a major threat to public health. British Medical J. 1998;317:609-11.

30. WHO Action Programme on Essential Drugs, How to investigate drug use in health facilities, WHO/DAP/93.1. 1993;1-92.

31. Laporte JR. Towards a healthy use of pharmaceuticals. Development dialogue. 1985;2:48-55.

32. Pallavi I, Shrivastava R, Sharma A, Singh P. Prescribe Pattern of Drugs and Antimicrobials Preferences in the Department of ENT at Tertiary Care SGM Hospital, Rewa, MP, India. Journal of Pharmaceutical and Biomedical Sciences. 2016;6:89-93.

33. Begum MM, Uddin MS, Rahman MS, Nure MA, Saha $\mathrm{RR}$, Begum T, et al. Analysis of prescription pattern of antibiotic drugs on patients suffering from ENT infection within Dhaka Metropolis, Bangladesh. Int J Basic Clin Pharmacol. 2017;6:257-64.

34. Deshmukh AC, Ghadlinge MS, Tamboli SB, Deshmukh JB, Chhabra RR. Study of rationality and utilization pattern of antimicrobials in ear, nose, throat outpatient department of Tertiary Care Hospital, Nanded. Int J Basic Clin Pharmacol. 2015;4:734-8.

35. Ain MR, Shahzad N, Aqil M, Alam MS, Khanam R. Drug utilization pattern of antibacterials used in ear, nose and throat outpatient and inpatient departments of a university hospital at New Delhi, India. Journal of Pharmacy and Bioallied Sciences. 2010;2:8.

36. Khan FA, Nizamuddin S, Salman MT. Patterns of prescription of antimicrobial agents in the Department of Otorhinolaryngology in a tertiary care teaching hospital. Afr J of Pha and Pha. 2011;5:1732-8.

37. Yadav P, Kanase V, Lacchiramka P, Jain S. Drug utilization trends in ENT outpatient department in a Teaching hospital. Int J Pharm Biol Sci. 2010;1:15360.

38. Pal A, Bhowmick S, Basu J, Chattopadhyay R, Paul SS, Chattopadhyay S. Study on Prescribing Pattern of Antimicrobials in ENT Department of a Tertiary Care Teaching Hospital in Bihar, India. World Journal of Pharmaceutical Research. 2015;4:1839-52.

39. Deshmukh AC, Ghadlinge MS, Tamboli SB, Deshmukh JB, Chhabra RR. Study of rationality and utilization pattern of antimicrobials in ear, nose, throat outpatient department of Tertiary Care Hospital, Nanded. Int J Basic Clin Pharmacol. 2015;4:734-8.

40. Ansari KU, Singh S, Pandey RC. Evaluation of prescribing pattern of doctors for rational drug therapy. Indian Journal of Pharmacology. 1998;30:436.

41. Padwal SL, Kulkarni MD, Deshmukh VS, Patil JR, Jadhav SS, Jadhav AD. Drug use pattern in the ear, nose, throat outpatient department of a rural tertiarycare teaching hospital. National Journal of Physiology, Pharmacy and Pha. 2015;5:212-6.

42. Raza UA, Khursheed T, Irfan M, Abbas M, Irfan UM. Prescription patterns of general practitioners in Peshawar, Pakistan. Pak J Med Sci. 2014;30:462-5.

43. Abubakar K, Abdulkadir R, Abubakar MR, UgwahOguejiofor JC, Abubakar SB. Pattern of Drug Utilization in the Treatment of Chronic Suppurative Otitis Media in a Tertiary Health Institution in Kaduna, Nigeria. Journal of Health Science. 2014;4:710.

44. Lisha JJ, Meenu C, Jayadevan S, Tambi C. Patterns of Antimicrobial therapy in acute tonsillitis: A crosssectional Hospital-based study from UAE. Annals of the Brazilian Academy of Sciences. 2014;86(1):4517 .

Cite this article as: Gupta SP, Poudel S, Gupta AP, Bashyal B, Baskota B, Sah AK, et al. A prospective cross-sectional study on prescribing pattern of antibiotics on patients suffering from ENT infections in tertiary care hospital, Pokhara, Nepal. Int J Basic Clin Pharmacol 2017;6:2303-10. 